\title{
A Study of the Simple Geometrical Relationship of the Main Monuments of Giza and a Possible Connection to Stars
}

\author{
Rodney Hale1, Andrew Collins ${ }^{2}$ \\ ${ }^{1}$ The Institution of Engineering and Technology, Stevenage, UK \\ ${ }^{2}$ Independent Researcher, Leigh-on-Sea, UK \\ Email: rhale@canopia.demon.co.uk, andrewcollinsweb@btinternet.com
}

Received 29 February 2016; accepted 17 April 2016; published 20 April 2016

Copyright (C) 2016 by authors and Scientific Research Publishing Inc.

This work is licensed under the Creative Commons Attribution International License (CC BY). http://creativecommons.org/licenses/by/4.0/

(c) (i) Open Access

\begin{abstract}
There have been many books and articles written with the purpose of trying to express an underlying master plan for the major pyramids of the Giza plateau. In this paper, a simple yet accurate geometrical layout, which also includes the Sphinx monument, is demonstrated with the aid of a well-known and widely used computer program. Furthermore, the positions of stars may be added to the same program, enabling the correlation of star positions to pyramids during the time frame of their construction to be determined with accuracy and simplicity.
\end{abstract}

\section{Keywords}

Giza, Pyramids, Gebel el-Qibli, Fourth Dynasty, Khufu, Kafr el-Gebel, Stars, Orion, Cygnus

\section{Introduction: A Master Plan at Giza?}

Over the last 200 years, there have been various attempts to show that the three main pyramids at Giza were positioned in accordance with a pre-determined master plan. If such a grand design does exist then it must have been the work of the principal surveyors behind the emergence of the well-known pyramid field during the Fourth Dynasty of Egypt's Old Kingdom period, ca. 2613-2498 BCE (von Beckerath, 1997).

Proposals for the existence of a master plan at Giza have focused on its three main pyramids - the Great Pyramid, Second Pyramid and Third Pyramid (henceforth G1, G2 \& G3). They have ranged from a common, rigid geometry (Agnew, 1838; Ballard, 1882; Legon, 1979) to alignments towards the cult centre of the sun-god Re at Heliopolis (Dash, 2011), and the placement of key monuments to observe the sun rise at the equinoxes and solstices (Goyon, 1970; Lehner, 1985; Lehner 1997; Quirke, 2001). 
In addition to these ideas, it has been proposed that the three main pyramids at Giza are positioned to reflect the astronomical positions of specific stars, in particular those of the belt stars of Orion, the so-called Orion Correlation Theory (Bauval \& Gilbert, 1994), and/or the three "wing" stars of the Cygnus constellation, the Cygnus-Giza Correlation (Collins, 2006; 2009; 2011a).

It is the purpose of this paper to show the presence at Giza of a simple cohesive grand design embracing not only the three main pyramids of the pyramid field, but also the Sphinx monument, which lies at the end of the causeway attached to the Second Pyramid, close to the eastern edge of the plateau. The authors demonstrate also how this grand design incorporates an original Datum point, as well as a north-south Datum line, along with associated star alignments in both the horizontal and vertical plane. In addition to this, a recent study vindicating the Orion Correlation Theory and dismissing the Cygnus-Giza Correlation (Orofino \& Bernardini, 2016) is discussed.

\subsection{Methodology}

Fundamental to work requiring the positioning of the major monuments in the Giza pyramid field is the use of an accurate map. The survey of the Giza plateau undertaken by Sir William Flinders Petrie in 1880-2 (Petrie, 1883) has in the past been employed for such purposes (Legon, 1979). Other attempts have used diagrams derived from Google Earth images (Orofino \& Bernardini, 2016).

In 1984, Dr. Mark Lehner of the Oriental Institute at the University of Chicago and David Goodman, a surveyor with the Ancient Egypt Research Associates (AERA), initiated a precise survey of the plateau at Giza under the name of the Giza Plateau Mapping Project (GPMP). Using the trigonometrical points generated by the survey, a calculated route of $6 \mathrm{~km}$ around the plateau arrived back at the starting point with an error of less than $2 \mathrm{~cm}$ (Goodman, 2007; Goodman \& Lehner, 2007). The full data of the survey have yet to be released, but digitally generated grid maps using a Geographic Information System (GIS) are available to the public (Miracle, 2011). The best of these maps offer a resolution of very nearly one pixel per metre, adequate for use in this paper (to see the GPMP base map, go to http://www.andrewcollins.com/page/articles/GPMP.htm).

The pixel position of each corner and central peak of each pyramid, and the position representing the face of the Sphinx, was entered into a spreadsheet of the Excel computer program. The table of results was then converted to metric units, and from this a correctly scaled map of the three main pyramids and Sphinx face was generated. By taking a number of measurements from the $100 \mathrm{~m}$ grid incorporated on the grid map an error of $+/-$ two pixels should be allowed, amounting to a placement error of up to $3 \mathrm{~m}$ on the ground. Other required data to be entered were the heights of the pyramids and of any viewpoint, all referenced to sea level.

It was a simple matter to add to the spreadsheet the altitudes and declinations of stars of interest at selected times using data offered by the Cartes du Ciel Skychart astronomical software. The accuracy is greater than the resolving power of the eye (Clark, 2010), so it was considered that no additional allowance for error was necessary. The angular positions of the stars are additionally scaled to be representative of their apparent linear metric distances, to allow direct comparison of the star positions with features on the ground.

With the information now available in the spreadsheet, all calculations and diagrams were carried out using the trigonometrical and plotting facilities integral to the software. Any misplacement arising from the correlation of specific stars to pyramid peaks can be shown both graphically and as displacement in metres.

\subsection{Equilateral Triangulation}

To turn first to the geometry of the Giza plateau: the basis for a geometric figure to fit into the plateau layout was first noticed by Hale in 2008 (Collins, 2009). By using the positions of the peaks of G1 and G3 as two of the three corners of an equilateral triangle, the third corner of the triangle falls on Gebel el-Qibli. This is a prominent rocky outcrop of the Maadi Formation that rises to a height of $59 \mathrm{~m}$ above sea level. At its base lies the plateau's main wadi, and some $400 \mathrm{~m}$ due north of its position is the face of the Great Sphinx (Aigner, 1983). Gebel el-Qibli offers a vantage point for viewing the whole plateau as has been recognised by those surveying the plateau. The Giza Plateau Mapping Project, for example, used Gebel el-Qibli as its own primary survey point (Lehner, 2011). The equilateral triangle thus defines the positions of the peaks of G1, G3 and the heights of Gebel el-Qibli (see Figure 1). However, the point where the third corner of the equilateral triangle falls on Gebel el-Qibli is more than just a good vantage point from which to observe the plateau and its monuments. As we shall see, it assumes an importance that, for this paper, merits its title of Datum point. 


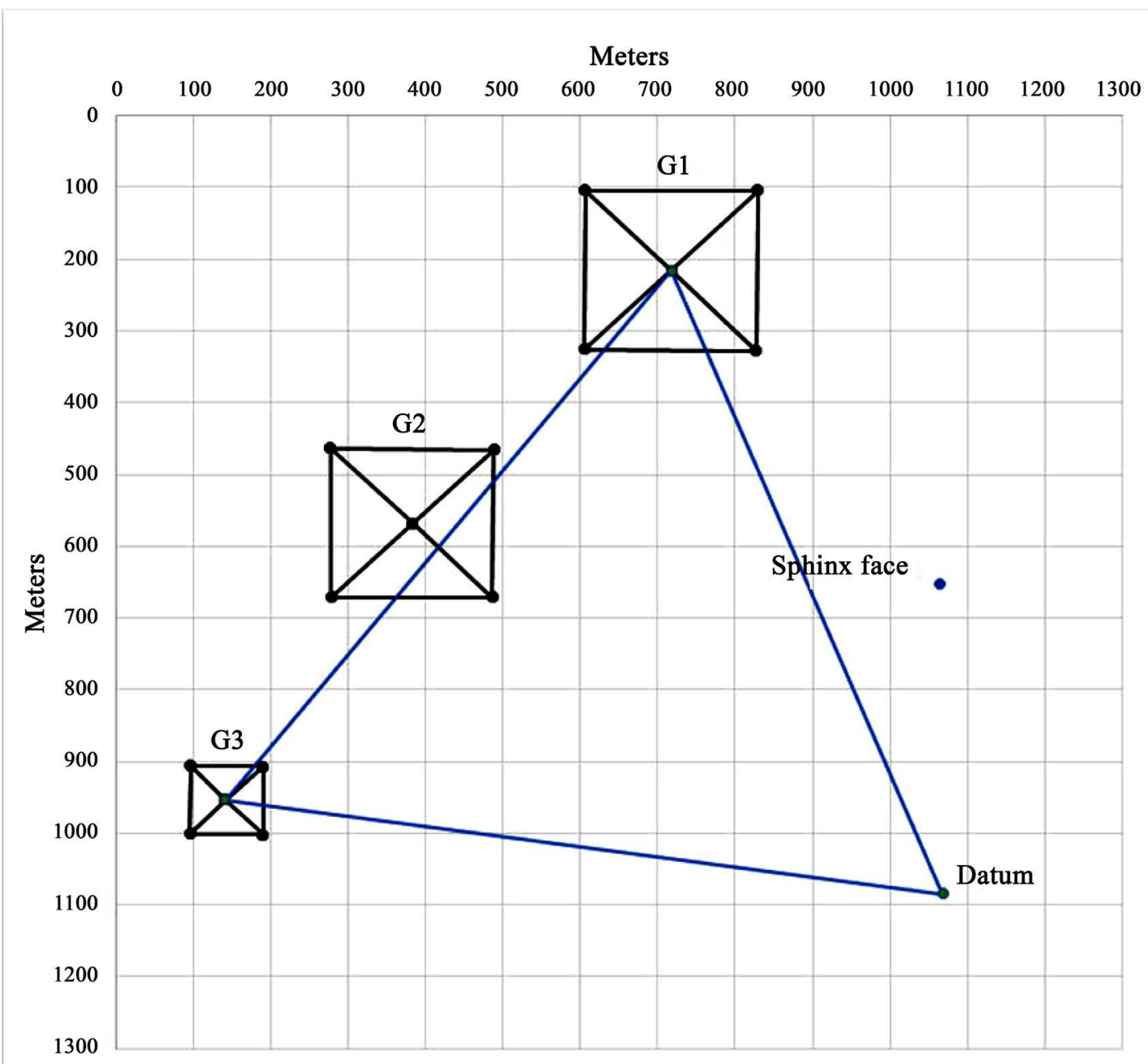

Figure 1. The plot of the equilateral triangle at Giza. The Datum point coinciding with the summit of Gebel el-Qibli is derived from the third corner of an equilateral triangle with its other two corners marking the peaks of G1 and G3. Having established the positioning of the Datum point it becomes clear that this could easily have acted as a survey point from which the extent of the pyramid field was determined through the use of very basic trigonometry (see Section 1.2).

\subsection{Right-Angled Triangulation}

The second triangle employed in this examination of Giza's inherent geometrical design is the well-known rightangled triangle, its sides with the ratio of three units, four units and five units of length. Starting from the Datum point as one corner, the distance from the Datum point to the peak of G2 represents the side of five units. The side of three units projects due north from the Datum point and the remaining side of four units turns at right angles to meet the line from the Datum point at the peak of G2 (see Figure 2).

The line projected due north from the Datum point, when carried further, intersects the east-west line of the G1 peak. The fact that the face of the Great Sphinx lies on this Datum line within $3 \mathrm{~m}$ of the halfway point between Gebel el-Qibli and the latitude corresponding with the peak of G1 seems beyond chance alone.

With the establishment of these two triangles and the Datum line it becomes clear that a number of related simple geometric figures can accurately be fitted into the plateau layout, all of which add to the idea of a grand design used in the creation of the pyramid field.

\subsection{Sphinx Knoll}

The Great Sphinx is carved from an outcrop of hard limestone that had protruded from the softer bedrock of the 


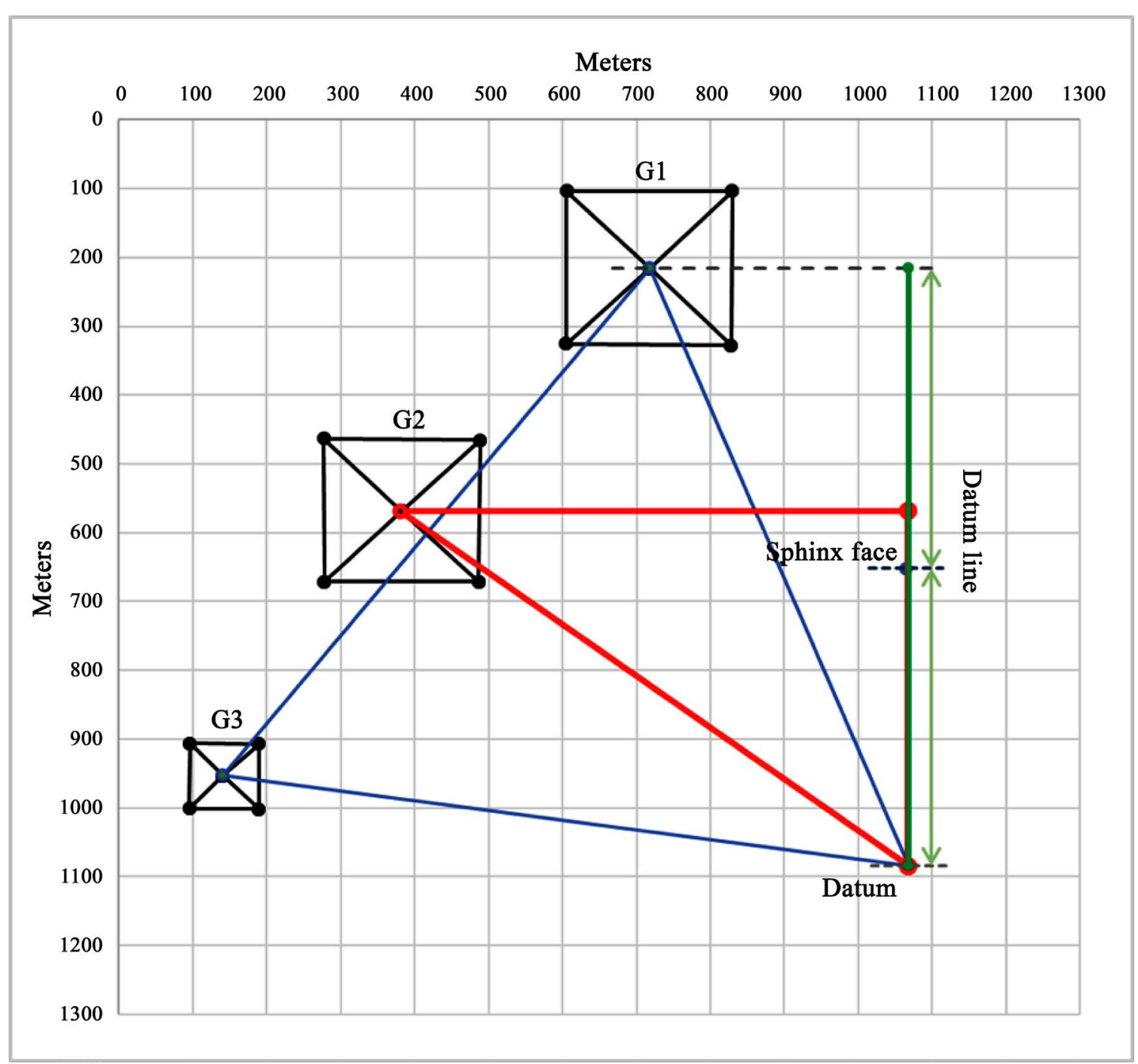

Figure 2. The plot of the 3-4-5 triangle at Giza shown in red, derived from a line drawn due north from the Datum point (see Section 1.2), combined with a perpendicular line westwards from the datum line, and a return line between the peak of G2 and the Datum point. The position of the equilateral triangle described in Section 1.2 is marked in blue. Note how the placement of the Sphinx monument falls on the Datum line, half way between the Datum point and a perpendicular line west from the Datum line to the peak of G1. This simple trigonometry defines the placement of 1) all three main pyramids at Giza; 2) the face of the Sphinx, and 3) the summit of Gebel el-Qibli.

underlying Mokattam Formation for anything up to several hundred thousand years before its acquisition for use in dynastic times (Aigner, 1983; Hawass \& Lehner, 1994). The presence of this prominent knoll almost exactly halfway along the Datum line implies that it might have been employed to determine the latitudinal position of G1's peak. In other words, the distance between Gebel el-Qibli and the Sphinx knoll was simply doubled to create the full length of the Datum line. This then defined a working base line for the geometrical layout of the pyramid field (see Figure 2 and Figure 6). If so, it means this knoll formed an integral role in the pyramid field's grand design, and must therefore have been important even before this time, a theory proposed by Serena Love. She surmises that in its original, unaltered form there might have been something unique about this protruding rock, perhaps a human-like appearance (Love, 2006). Significantly, she suggests the Sphinx knoll "may have even influenced people's later choice in settling and burying their dead [on the plateau]", and was interpreted by those who arrived on the plateau in Pre-dynastic times as a "monumental relic" (Love, 2006). The authors concur with this observation, and further propose that the Sphinx knoll was used in strategic conjunction with Gebel el-Qibli to determine the extent of the Fourth Dynasty pyramid field through the establishment of the 
Datum point and north-south Datum line.

\subsection{The Pyramid Arc}

A geometric theorem states that any three points lie on a circle, providing the points are not on a straight line. We have three pyramid peaks which are not on a straight line, therefore adding appropriate instructions to the spreadsheet enables the length of the radius of the circle passing through the three pyramid peaks and its direction to be found. Choosing to draw a radius line from the peak of G2 (the reason is dealt with later), this line passes very close to the Datum point, which lies at a distance of $858 \mathrm{~m}$ southeast of the pyramid peak (see Figure 3). The length of the radius from the peak of G2 to the centre of the Pyramid arc, located in the area of the village Kafr el-Gebel ( $29^{\circ} 57^{\prime} 47^{\prime \prime} \mathrm{N}, 31^{\circ} 09^{\prime} 01^{\prime} \mathrm{E}$ ), is $2384 \mathrm{~m}$ (and from the Datum point $1526 \mathrm{~m}$ ). The importance of this pyramid arc circle is explained below.

\section{Star-to-Peak Correlations at Giza and Their Usefulness in Understanding the Pyramid Field's Proposed Grand Design}

Arguably the most popular theories concerning a proposed grand design at Giza focus around the idea that its three main pyramids were positioned to reflect the astronomical positions of specific stars. Two potential star correlation theories have emerged as workable in this regard. The first has become known as the Orion Correlation Theory. This argues that the peaks of the three main pyramids - those of Khufu, Khafre and Menkaurewhen viewed collectively from an overhead position, reflect the astronomical positions of the "belt" stars

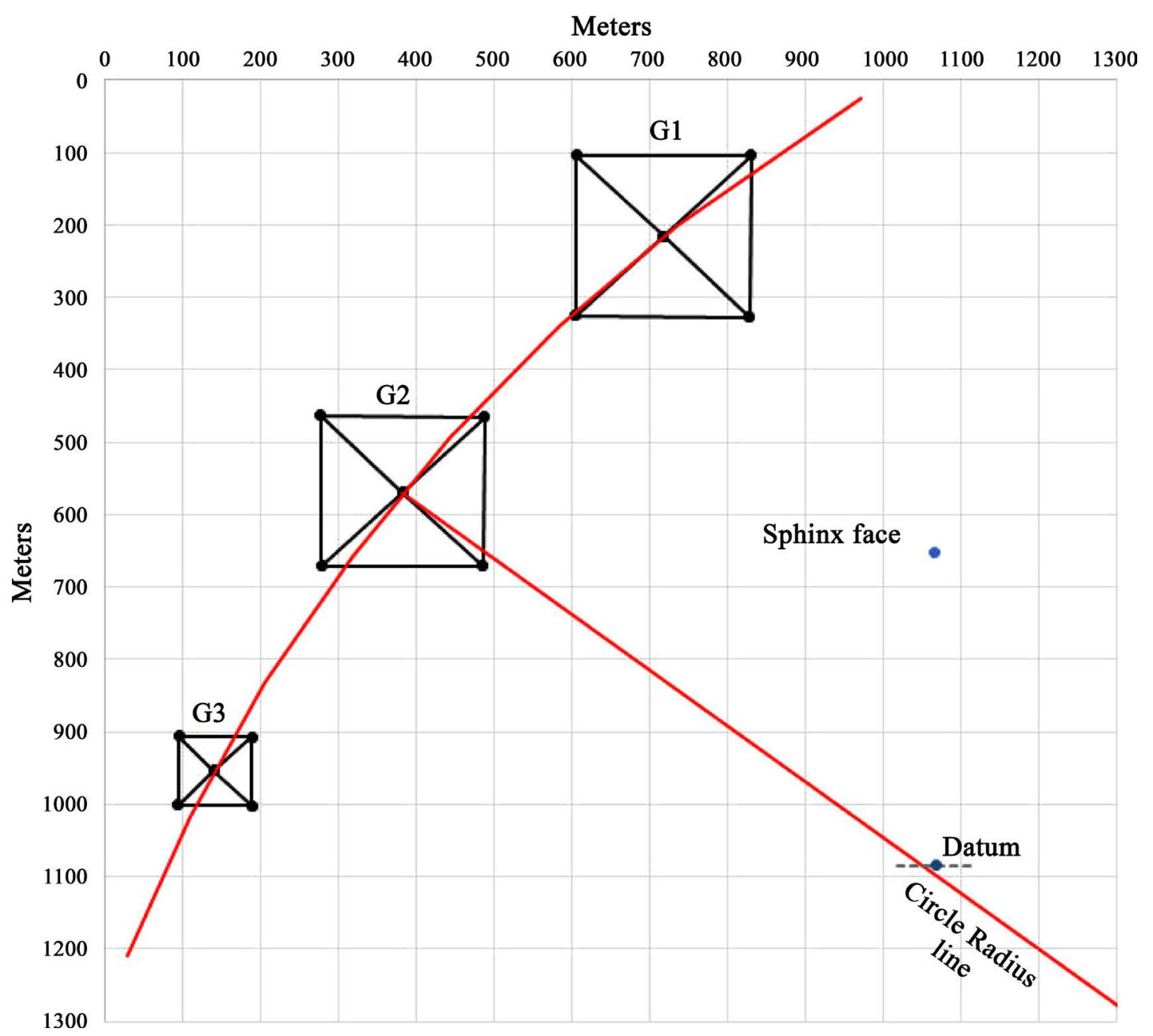

Figure 3. Giza base map with pyramid arc and radius line indicated in its relationship to the peak of G2 and the Datum point. 
of Orion (Bauval \& Gilbert, 1994; Bauval, 2006). Another theory, the Cygnus-Giza Correlation, suggests that instead of the Orion belt stars being used to determine the geographical positions of the three main pyramids, this role works better using the three basic "wing" stars of the Cygnus constellation (Collins, 2006; 2009; 2011a).

To the human eye, the astronomical positioning of both the Orion belt stars-Alnitak ( $\zeta$ Orionis), Alnilam ( $\varepsilon$ Orionis) and Mintaka ( $\delta$ Orionis) — and the wing stars of Cygnus—Rukh ( $\delta$ Cygni), Sadr ( $\gamma$ Cygni) and Gienah ( $\varepsilon$ Cygni) — match very well the geographical placement of the peaks of, respectively, G1, G2, and G3. Since both Orion and Cygnus are thought to have featured in the cosmic geography of the ancient Egyptians when the Giza pyramid field emerged under the kings of the Fourth Dynasty (Bauval, 2006; Collins, 2009; 2011a, b), it is possible that one or other of these constellations could have been used in determining the placement of the three main pyramids at Giza.

A recent study examining both of these potential star-to-peak correlation theories at Giza found that the Orion Correlation Theory was statistically more valid than the Cygnus-Giza Correlation (Orofino \& Bernardini, 2016). However, the present authors have reviewed the evidence presented in this study and find its conclusions contrary to their own in this regard.

It was therefore felt that the matter of star-to-peak correlations at Giza deserved a full re-evaluation in the light of this renewed interest in the subject.

\subsection{Using the Star Data Loaded into the Spreadsheet}

One use of the spreadsheet data outlined in Section 1 with respect to the basic trigonometry revealed in connection with the geographical placement of the three main pyramids at Giza is the ease with which the accuracy of star-to-peak correlations can also be examined. This is achieved by converting the star positions to their equivalent metric placements. Not only can the star positions be overlaid on the mapped positions of the pyramid peaks, but the actual displacement of each star from the particular peak with which it is associated can also be displayed in metres. There is no need therefore to estimate the accuracy of any ground-sky correlation by eye alone. The original map accuracy is relevant here; an error of up to $3 \mathrm{~m}$ must be borne in mind, although any mapping inaccuracies will prevail equally for all correlation results. The method used in the spreadsheet calculations allows the orientation, scale and positioning of a chosen star group to be adjusted to produce the best match. In the instances used here the best matches are considered to be when the displacement for each of the stars from their peaks reaches an approximately equal minimum, the same methodology adopted in the above mentioned study of possible star correlations at Giza by Vincenzo Orofino and Paolo Bernardini (Orofino \& Bernardini, 2016).

\subsection{Ground-Sky Correlations at Giza}

To examine the accuracy of these ground-sky correlations, an origin date of 2550 BCE is employed. This corresponds with the earliest construction date for G1 (the Great Pyramid), taken to be the sepulchral tomb of Khufu, who assumed the throne in ca. 2552 BCE (von Beckerath, 1997). He was the first of the three kings associated with pyramid building at Giza during the Fourth Dynasty. Orofino and Bernardini adopt this same date for their own examination of possible star correlations at Giza (Orofino \& Bernardini, 2016). It is obviously realised that the three main pyramids at Giza were not built at the same time, so a period of 50 years is proposed for the completion of all three pyramids under the kings Khufu, Khafre and Menkaure. Thus observable star-to-peak correlations should reflect a time period of 50 years, thus ca. 2550 - 2500 BCE.

As per the existing study, just two sets of stars are employed in this examination of star correlations at Giza. These are the belt stars of Orion—Alnitak, Alnilam and Mintaka—and the wing stars of Cygnus—Rukh, Sadr and Gienah. Both sets of stars accurately reflect the geographical placement of, respectively, the peaks of G1, G2 and G3 when viewed from directly overhead. The current authors have attempted to establish whether other groupings of three stars, which also feature in the cosmic geography of the pyramid age, might match the geographical positions of the Giza pyramid peaks, but none have been found. They therefore feel justified, like Orofino and Bernardini in their own study, in using only the Orion belt stars and Cygnus wing stars in this examination of potential star correlations at Giza.

Even in the cases of Orion and Cygnus, star-to-peak correlations that would never have been seen by observers from the ground, and thus only ever had a symbolic value to the ancient Egyptians, can mean very little. More important would have been the actual witnessing of star-to-peak relationships. This would have confirmed 
how the architects of the pyramids had planned these monuments to successfully unite sky and earth in a manner that would have satisfied the spiritual needs of the people.

\subsection{Star-To-Peak Correlations in the Horizontal Plane}

With these thoughts in mind, a position can be found to the southeast of the three main pyramids at Giza where during the epoch of construction on the pyramid field, ca. 2550 - 2500 BCE, the wing stars of Cygnus would have been seen to set, one after the other, into the three pyramid peaks-Rukh into G1, Sadr into G2 and Gienah into G3. In previous publications (Collins, 2009; Collins, 2011a), the location from which this spectacle could have been observed is referred to as the Convergence Point, the term adopted in this current paper. The accuracy of the settings of these stars into their respective pyramid peaks is remarkable, the error being within 9 arc minutes (see Figure 4).

In addition to the synchronisation between the setting of the stars and the pyramid peaks, it is to be noted that the height of each pyramid can be visually linked to a star. So not only is there a link between the geographical position of a pyramid and its associated star, but a match exists also between the height of each pyramid and the setting path of its corresponding star.

Thus from the advantageous position of the Convergence Point, located $2940 \mathrm{~m}$ southeast of the peak of G2 (2082 m distance from the Datum point), observers could have watched the three Cygnus stars set into their corresponding pyramid peaks. The line on which the Convergence Point is located coincides also with the centre of the arc circle created by the pyramid peaks (see Figure 5 \& Figure 6). This provides additional evidence that the Convergence Point was not simply a random position, but conformed to an emerging grand design determined by the placement of the pyramids on the nearby pyramid field (for more information on the Convergence Point see Section 3 of this paper).

Practical tests demonstrate that few people possess an observational accuracy better than 3.5 arc minutes, and in addition to this a so-called "smearing" effect has to be taken into account when observing near the horizon due to the greater mass of air through which light travels (Schaefer, 1993). Thus an observer at the Convergence Point would have seen a match of stars to pyramids of great visual accuracy, adding weight to the authors' opinion that this ground-sky synchronisation was a deliberate act created as part of Khufu's pyramid complex at Giza.

\subsection{The Similarity of G2 Azimuth Features as Viewed from Points Discussed in This Paper}

G2 as seen from the Datum point $306.95^{\circ}$.

$\mathrm{G} 2$ as seen from the centre of the pyramid arc $307.65^{\circ}$.

G2 as seen from the Convergence Point $307.55^{\circ}$.

G2 as seen along the hypotenuse of the 3-4-5 triangle $306.87^{\circ}$.

All of these azimuth bearings relating to the line between the peak of G2 and the Convergence Point are within $1^{\circ}$ of variation, making it unlikely that the features placed on this line are random and without purpose.

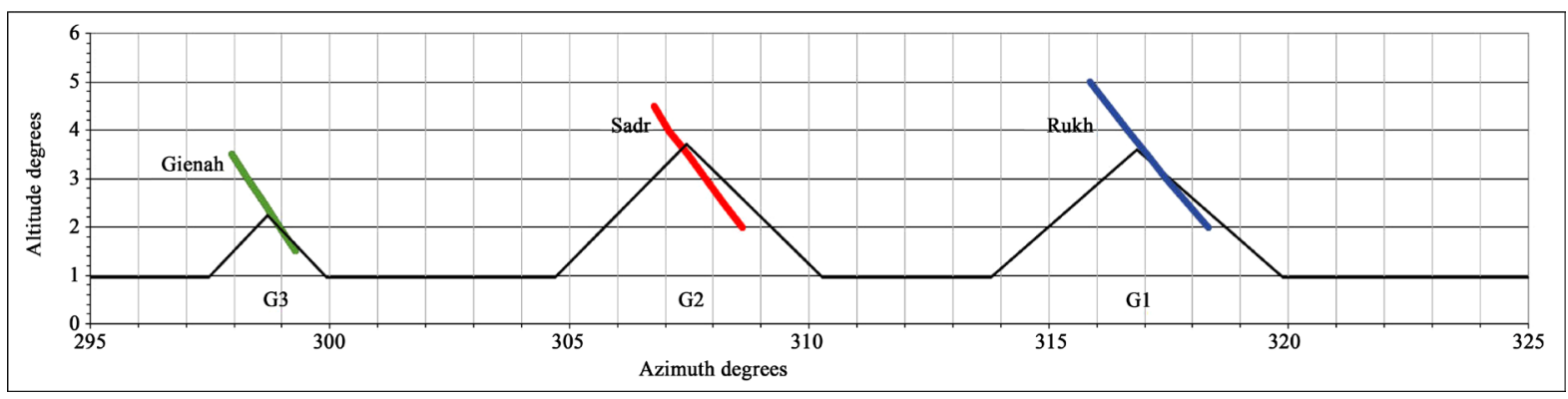

Figure 4. Plot of setting Cygnus wing star trails as viewed from the Convergence Point 2940 m southeast of the peak of G2. The green line passing through the peak of G3 (left) denotes the setting of the star Gienah ( $\varepsilon$ Cygni). The red line passing through the peak of G2 (centre) denotes the setting path of Sadr ( $\gamma$ Cygni), and the blue line passing through the peak of G1 (right) denotes the setting path of Rukh ( $\delta$ Cygni). During the epoch of 2550 - 2500 BCE each star set one after the other into their respective peaks, beginning with G3 and ending with G1. This would have created a visual spectacle that may well have formed an integral role in Giza’s grand design from the outset. 


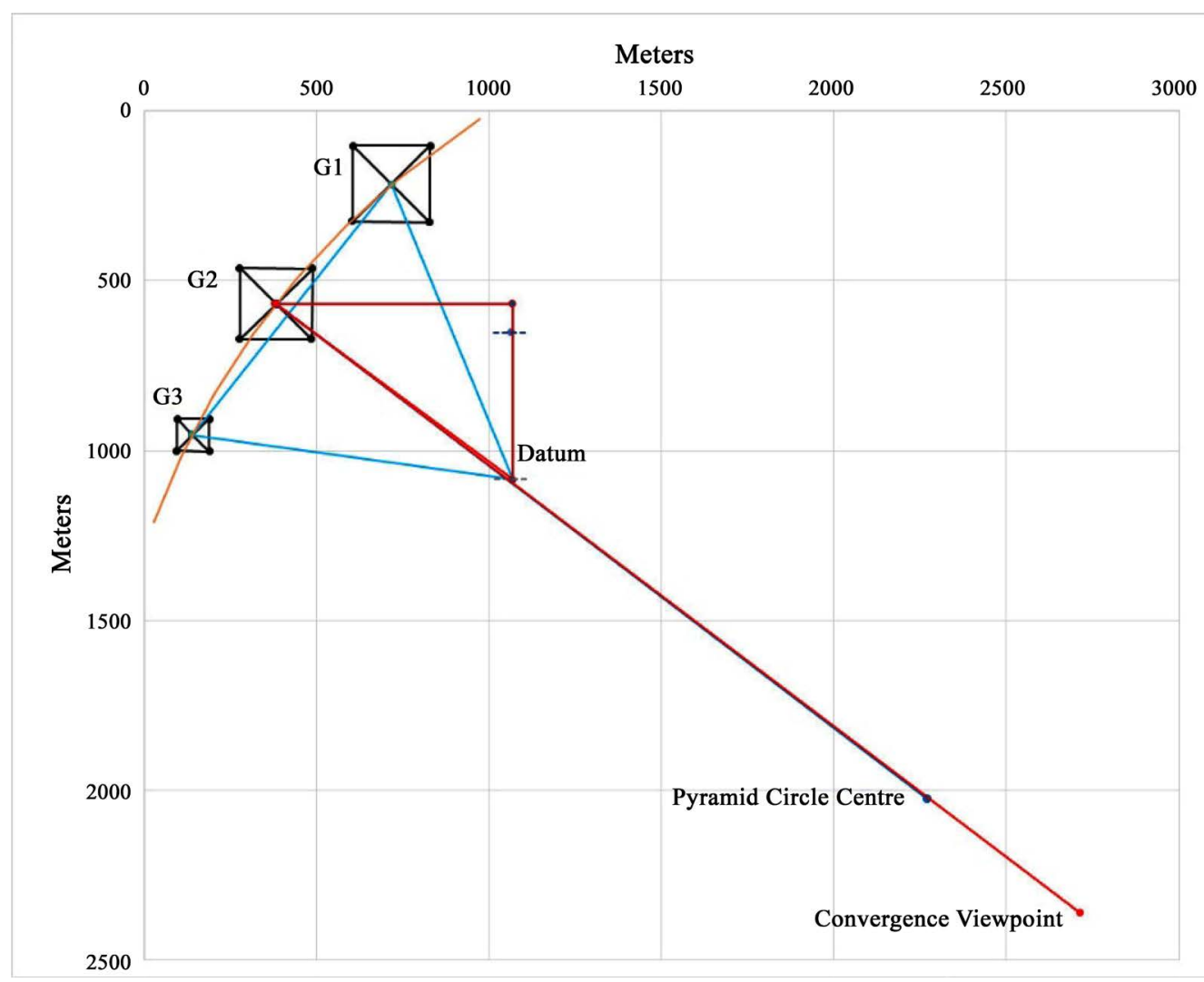

Figure 5. Base map with the three main pyramids of Giza overlaid with the arc circle curve, the equilateral triangle and the 3-4-5 triangle. The line extending from the peak of G2 to the Convergence Point is also shown with the Datum point and Pyramid Circle Centre marked.

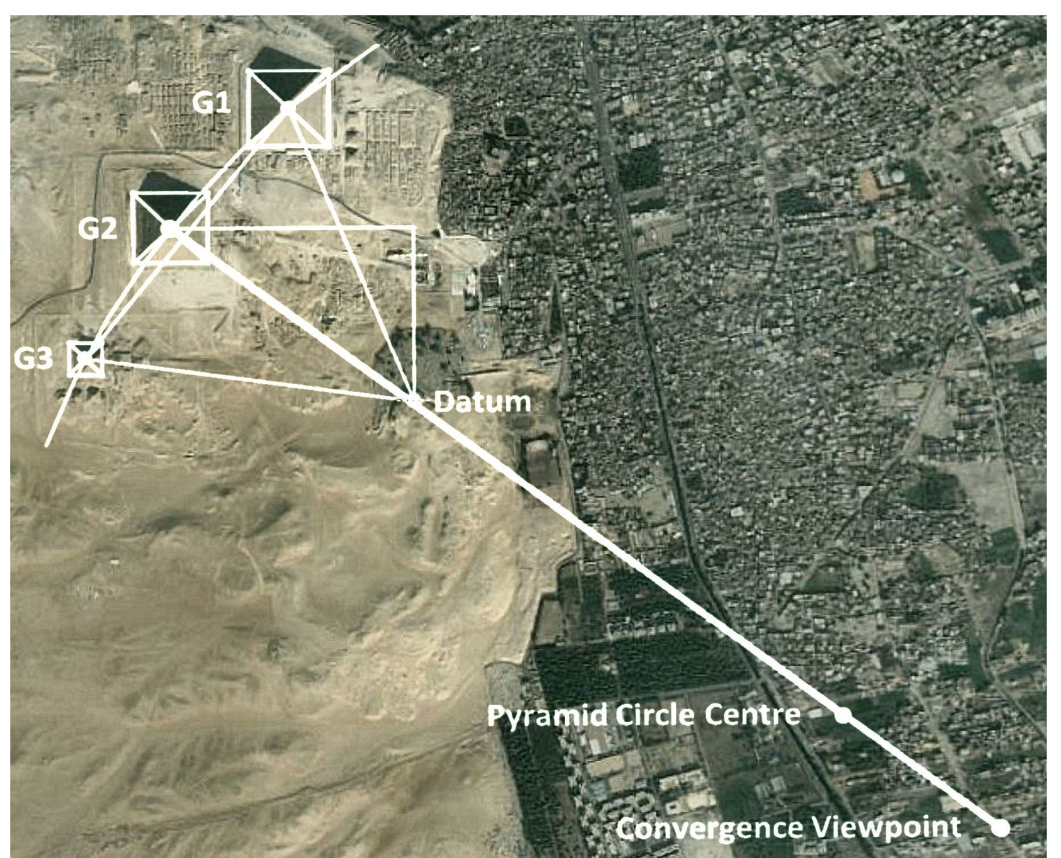

Figure 6. Satellite image of the three main pyramids of Giza overlaid with the arc circle curve, the equilateral triangle and the 3-4-5 triangle. The line extending from the peak of G2 to the Convergence Point is also shown with the Datum point and Pyramid Circle Centre marked. Note the position of the Sphinx (satellite image copyright: Google Earth/Digital Globe, 2016). 
An examination of the spreadsheet data shows that the stars of Orion's belt are unable to offer a similar visual spectacle. Both the orientation of the pyramids and the manner the Orion belt stars traversed the sky during the epoch of 2550 - 2500 BCE meant that there was never an opportunity for these stars to synchronise with individual pyramid peaks. Moreover, a distance of more than $10 \mathrm{~km}$ would have been required before the $3^{\circ}$ width of the Orion belt stars matched the apparent width of the three pyramid peaks at Giza. Even if the pyramids had been visible at this distance, the relative height of their peaks would have been below the extinction level of the Orion belt stars.

\subsection{Star-to-Peak Relationships in the Vertical Plane}

In Section 2.2, it was pointed out that non-visual matches between individual stars and pyramid peaks are of less value to correlation theories, since they can only ever be theoretical in nature and unobservable in practice. Having said this, it is important to look at potential star-to-peak correlations in the vertical plane to examine their possible connection with the star-to-peak alignments in the horizontal plane outlined in Section 2.3. Using the data from the spreadsheet it is a simple process to produce diagrams showing the overhead matches between the peaks of the three main pyramids at Giza and both the Cygnus wing stars and Orion's belt stars. These are shown in Figure 7 and Figure 8.

These diagrams result from plotting the positional data available, and as pointed out by Orofino and Bernardini in their own study, resulting data of this kind can be subjected to further statistical scrutiny (Orofino \& Bernardini, 2016). However, the authors of this paper consider this procedure unhelpful since it relates solely to overhead correlations, which at best played a symbolic function alone. Never could they have had a visual function like that described in connection with the Cygnus wing stars matching the pyramid peaks in the horizontal plane. From the diagrams, which illustrate the actual situation during the epoch of 2550 - 2500 BCE, it can be seen that Cygnus's wing stars are by a small margin a more accurate match to the pyramid peaks than those of Orion's belt stars. More significantly, the order of the three Cygnus wing stars featured in this overhead match is the same as that seen in connection with the star-to-peak synchronisation in the horizontal plane. Thus the Cygnus-Giza Correlation works both in the horizontal plane and in the vertical plane. This is completely lacking in the case of the Orion Correlation Theory, which exists only in the vertical plane.

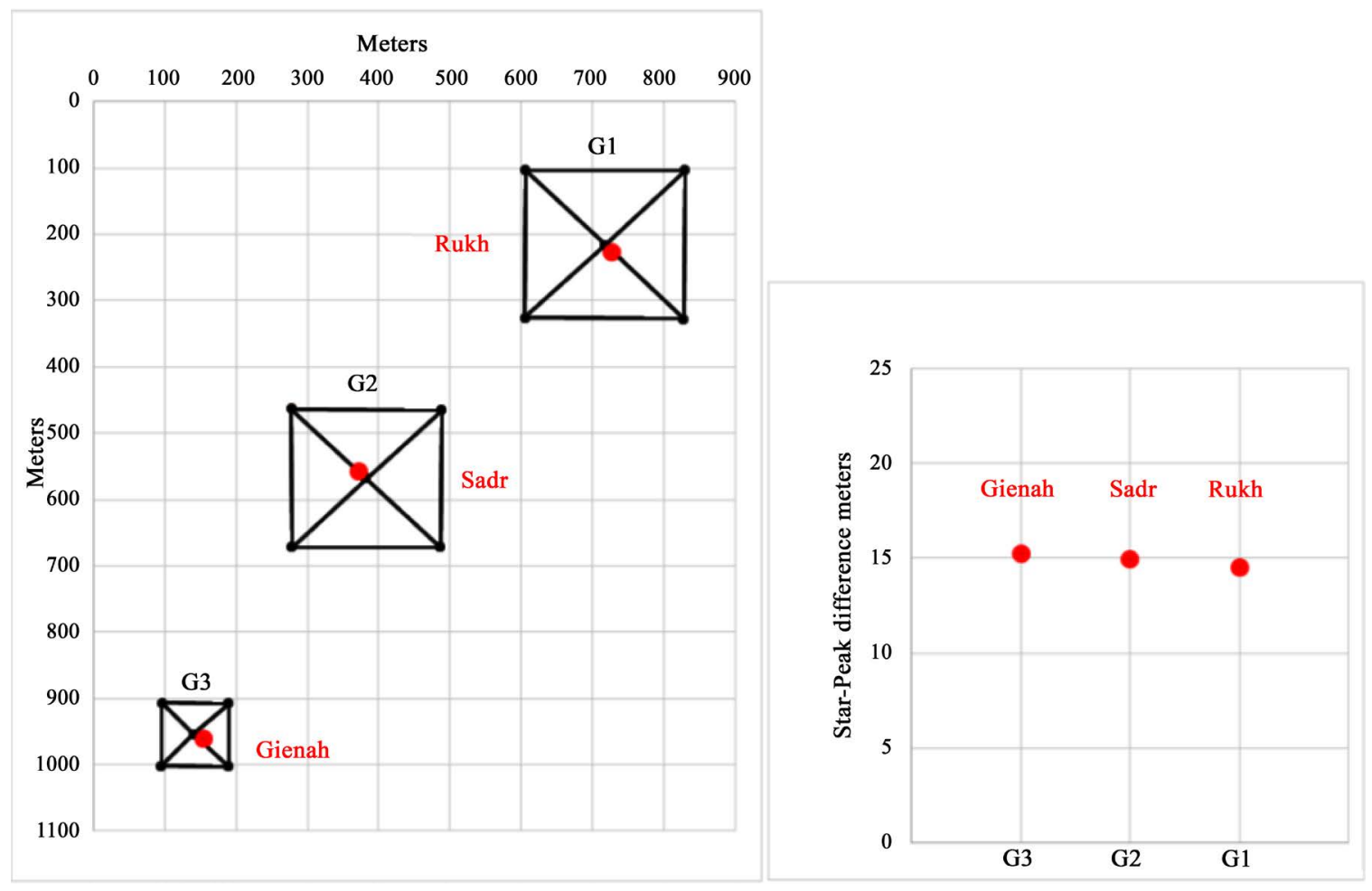

Figure 7. The wing stars of Cygnus matched against the pyramid peaks of G1, G2 and G3. 


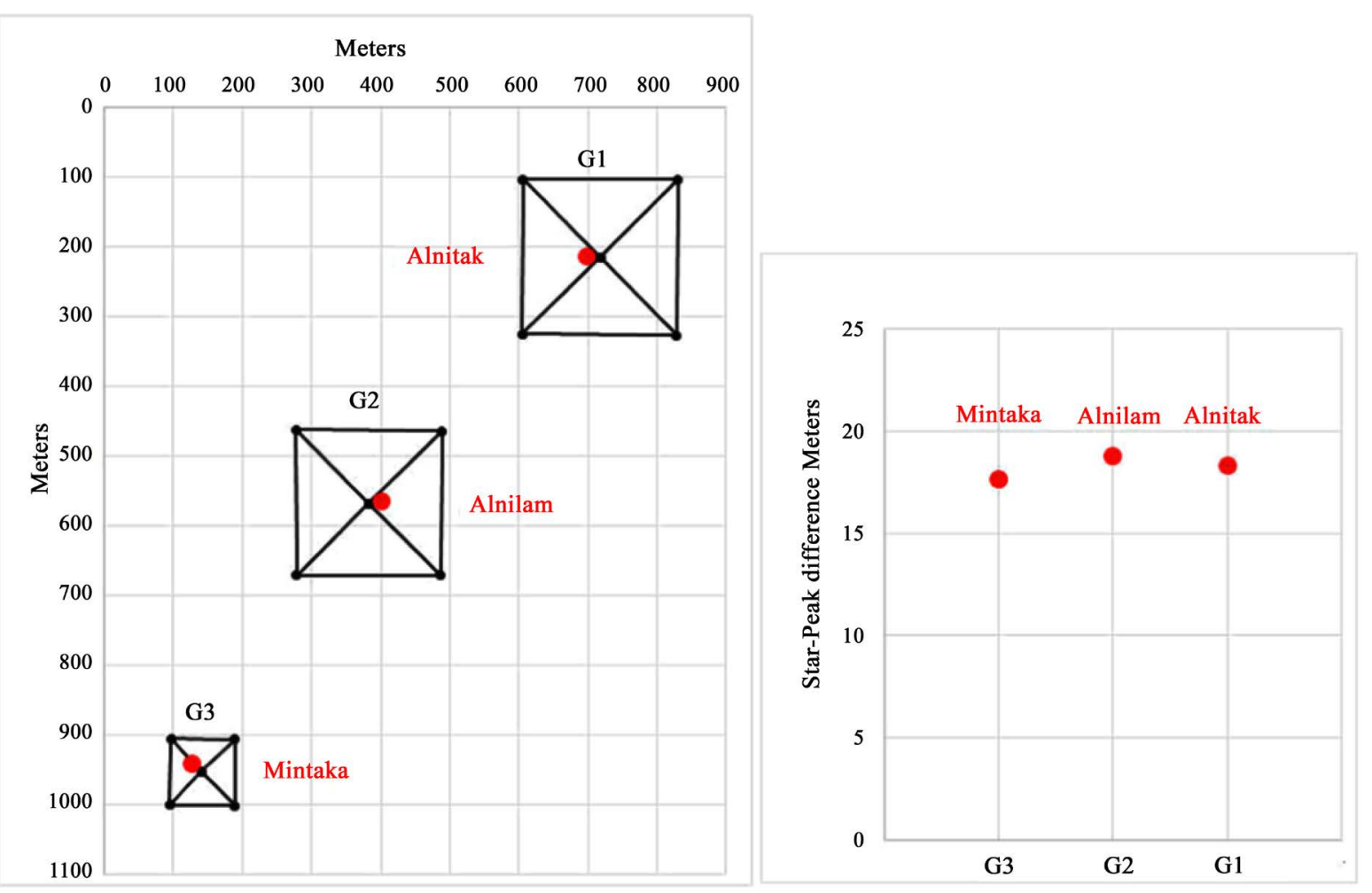

Figure 8. The belt stars of Orion matched against the pyramid peaks of G1, G2 and G3.

\subsection{Matching the Heights of Pyramids to Corresponding Stars}

In their vindication of the Orion Correlation Theory Orofino and Bernardini find a matching correspondence between the magnitude of the Orion belt stars and the heights of the three Giza pyramids when viewed from a suitable vantage point, something they do not find in the Cygnus-Giza Correlation (Orofino \& Bernardini, 2016). However, there is a fundamental problem in making such a comparison. Orofino and Bernardini acknowledge that the stars Mintaka and Alnilam are variable, in that they get brighter and dimmer on a regular basis. They go on to make their calculations based on each star's average magnitude. Yet in the case of the middle star of Orion's belt, Alnilam, its spectral variability changes to such a degree that for much of the time its magnitude almost matches that of neighbouring Alnitak. When this happens the two stars become virtually indistinguishable to the human eye. This makes the Orion belt stars unsuitable as visual representations of the pyramids based on height measurements alone.

In addition to this, the current authors consider comparing the relative heights of the pyramids against the magnitude of stars pointless if no direct visual connection can be made between the two mediums, and this would have been impossible in the case of the Orion belt stars. As stated in Section 2.4, the Giza pyramids could never have synchronised with their corresponding star as all three Orion belt stars rose and set from the same approximate positions in the epoch of 2550 - 2500 BCE. It seems of far greater significance that the peaks of the three pyramids accurately matched the descent paths of the Cygnus wing stars when observed from the Convergence Point.

\subsection{Deneb ( $\alpha$ Cygni)}

A further criticism of the Cygnus-Giza Correlation cited by Orofino and Bernardini is that, in addition to the three basic wing stars of Cygnus, two other stars of the constellation fall on the plateau within any kind of ground-sky overlay, and yet neither play a role in the correlation. These additional stars are Deneb ( $\alpha$ Cygni) and Eta Cygni ( $\eta$ Cygni) (Orofino \& Bernardini, 2016). Although it is correct that neither star is marked on the plateau by a significant monument, the authors can demonstrate that they do have roles in the Cygnus-Giza Correlation theory. The bright star Deneb could have been seen setting exactly into the peak of G2 when standing on 
the summit of Gebel el-Qibli (see Figure 9) during the main epoch of construction on the pyramid field, 2550-2500 BCE.

Gebel el-Qibli is located immediately to the west of the recently discovered "Lost City of the Pyramids". This extensive settlement acted as a workers' village and bustling port for those employed in construction and maintenance on the pyramid field (Lehner, 2013). It was separated from the pyramid field to the north by a $200 \mathrm{~m}$ long, $10 \mathrm{~m}$ high wall of large stone blocks known as Heit el-Ghurab ("Wall of the Crow"). That privileged individuals, perhaps attached to this settlement, could have ascended Gebel el-Qibli to watch Deneb set precisely into the peak of G2 strengthens the case for Cygnus having been important to the cosmological beliefs of the pyramid builders during the Fourth Dynasty. Although it must be assumed that G2 was built after G1, the slight movement of Deneb across one to two generations, due to the processes of precession, would not have created any noticeable change to this star-to-peak correlation.

The visual spectacle of seeing Deneb set into the peak of G2 when standing on Gebel el-Qibli cannot be unconnected with the ability to watch the three Cygnus wing stars setting one after the other into the peaks of the three main pyramids at Giza when positioned at the Convergence Point. Remember, the summit of Gebel el-Qibli is located on the same northwest-southeast line that connects the peak of G2 with both the centre of the pyramid circle and the Convergence Point.

\subsection{Eta Cygni ( $\eta$ Cygni)}

The other Cygnus star cited by Orofino and Bernardini as having no part to play when the peaks of the three main pyramids are synchronised with the Cygnus wing stars is Eta Cygni ( $\eta$ Cygni). In contrast to this claim, the current authors find that this star falls on the line connecting G2 to the Datum point and beyond to the pyramid arc centre and Convergence Point (see Figure 10). Not only does the location on the plateau of Eta Cygni present further confirmation of the importance of this line on the landscape, but it also shows that the pyramid field's suspected grand design embraced all five of the Cygnus stars cited by Orofino and Bernardini in their own study (Orofino \& Bernardini, 2016).

\section{Exploring the Convergence Point}

One final matter to address is the nature of the Convergence Point. Was it important during the Pyramid Age, and what remains there today? Geographically, it is located on Zaghloul Street (29 $\left.57^{\prime} 36^{\prime \prime} \mathrm{N}, 31^{\circ} 9^{\prime} 17^{\prime \prime} \mathrm{E}\right)$, a short distance south of Kafr el-Gebel, a suburb of the much larger village of Nazlet el-Batran. Although no excava-

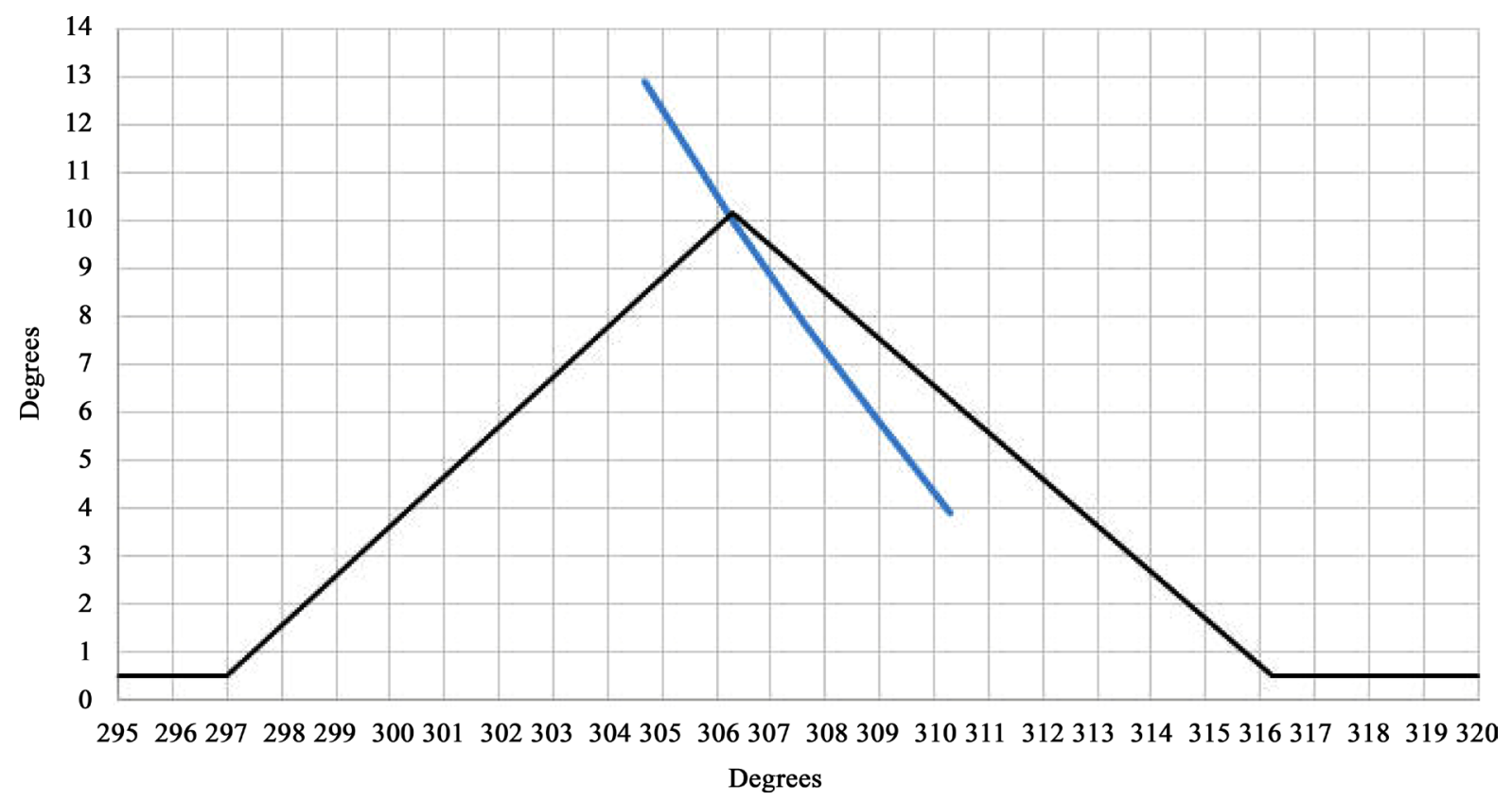

Figure 9. Plot showing the setting of Deneb ( $\alpha$ Cygni) into the peak of G2 as viewed from the summit of Gebel el-Qibli. 


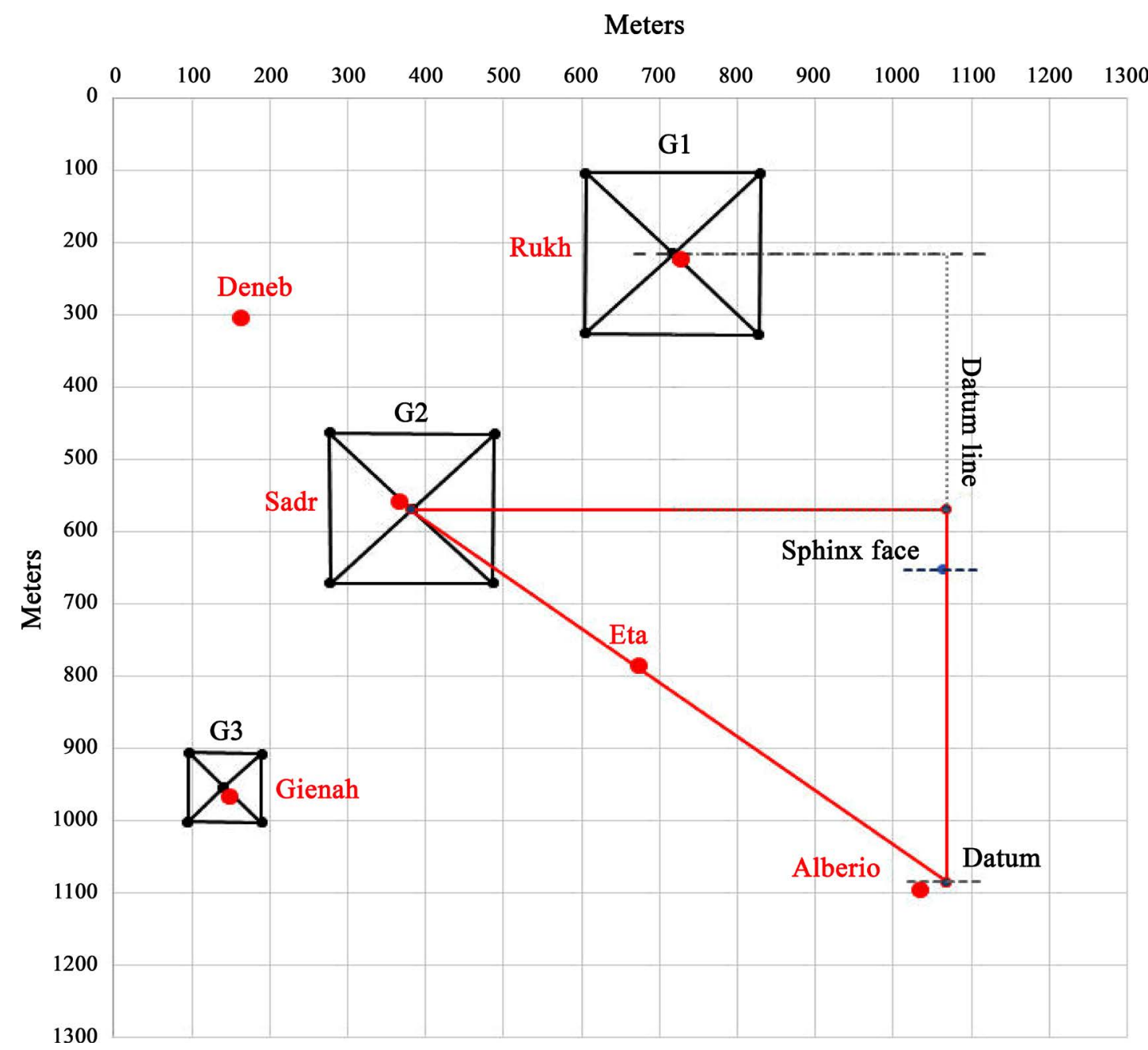

Figure 10. The principal stars of Cygnus overlaid on the plateau at Giza, with Eta Cygni falling on the line between the peak of $\mathrm{G} 2$ and the Datum point.

tions have taken place in the vicinity of the Convergence Point, an extensive settlement of mud-brick buildings is known to have extended from the position now occupied by the modern village of Nazlet el-Samman, east of the Giza pyramid field, southeast through the villages of Nazlet el-Sissi, Nazlet el-Batran and Kafr el-Gebel (Hawass \& Senussi, 2008). This settlement was unearthed in the late 1980s and early 1990s during the construction of a new sewage system as part of the Greater Cairo Waste Water Project initiated by American British Consultants (AMBRIC) to prevent the further rising of wastewater close to the plateau at Giza. Several thousand pieces of pottery were found, much of it dating to the Old Kingdom, along with mud sealings of Khufu and Khafre. The remains of the mud-brick buildings, along with the pottery found, suggest that this extensive settlement formed part of the pyramid city associated with the cult of Khufu (Hawass \& Senussi, 2008).

\subsection{Zaghloul Street Levees}

In addition to these discoveries, traces of levees that once ran from Nazlet el-Samman all the way to Kafr el-Gebel and beyond, have been detected running coincident to Zaghloul Street using data from the Shuttle Radar Topography Mission (SRTM) - see Figure 11. These are thought to indicate the position of a dyke or berm marking the western limit of the Nile floodplain towards the end of the Fourth Dynasty, ca. 2550 - 2500 BCE (Lutley \& Bunbury, 2008).

The path of the levees denoted today by Zaghloul Street appears connected with the discovery in 1993 and 1994 of a colossal wall 650 m south of Pyramids Road in Nazlet el-Samman (close to where the road forks be- 


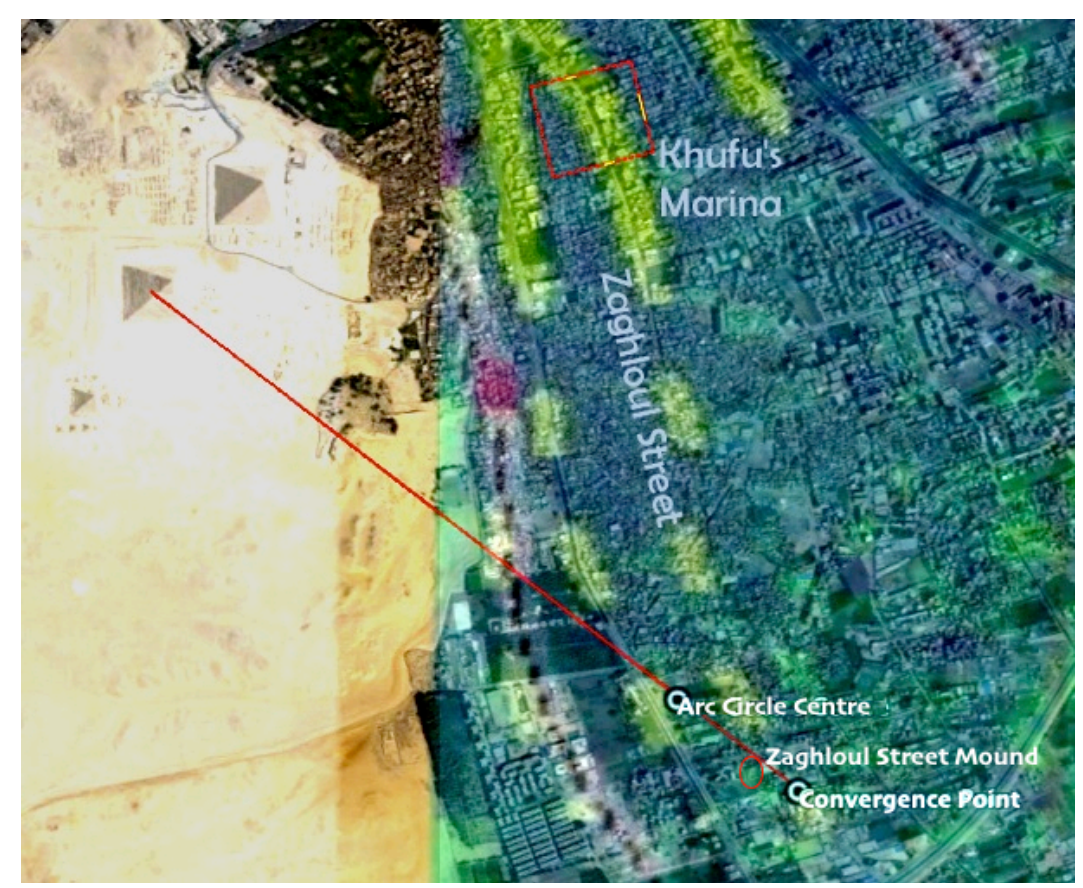

Figure 11. Satellite map overlaid with proposed positions of levees (marked in broken yellow lines) existing ca. 3000 - 2500 BCE (after Lutley \& Bunbury, 2008). Note the one corresponding with Zaghloul Street, and the position of the Convergence Point, both of which would have been close to the western edge of the Nile floodplain during Khufu's reign. This fact seems confirmed by the discovery of sections of walls (marked as short yellow lines) belonging to what is thought to be Khufu's marina (shown in red), after Lehner, 2014 (satellite image credit: Google Earth/Digital Globe, 2016).

fore turning south towards Nazlet el-Batran). Constructed from huge limestone blocks topped with a layer of basalt slabs, three sections of this wall have so far been uncovered (see Figure 11). The largest of these is $70 \mathrm{~m}$ in length (Hawass, 1997) and lies on the same north-south alignment as the proposed Zaghloul Street levees (Lehner 2014). The wall fragments are thought to belong to an enormous marina that linked the nearby Nile channel with Khufu's pyramid complex, in particular the site of his valley temple, which is today lost beneath the streets of Nazlet el-Samman (Lehner, 2014).

\subsection{Zaghloul Street Mound}

Satellite data examined by the authors show a noticeable area of high ground some $120 \mathrm{~m}$ to the northwest of the Convergence Point. It rises to a height of just over $21 \mathrm{~m}$ above sea level in an oval-shaped area oriented roughly north-south. Surrounding it to the northeast and southwest is a further stretch of high ground some $250 \mathrm{~m}$ in length, which climbs from $18 \mathrm{~m}$ to $20 \mathrm{~m}$ above sea level (see Figure 12).

This island of land, which we shall refer to as the Zaghloul Street Mound, is unique to the area. Indeed, between the peak of G2 and the Convergence Point it is the only noticeable area of high ground other than Gebel el-Qibli and an area of land marked by a grove of cultivated trees (see Figure 13). Thus its presence seems unlikely to be the result of a natural deposition of Nile mud and silt across a prolonged period of time. Significantly, the mound is close to the line between the Convergence Point and the three main pyramids of Giza (see Figure 11).

It seems probable that the Convergence Point and the Zaghloul Street Mound were located close to the western limit of the Nile channel as it would have appeared ca. 2550 - 2500 BCE. Plausibly, both sites were attached to a place of debarkation, a dyke or berm perhaps, used by boats arriving from the nearby city of Memphis, the capital of Lower Egypt from Early Dynastic times. If correct, both the Convergence Point and the mound might have been used in a ritual capacity, perhaps in coordination with the star-to-peak correlation featuring the Cygnus stars, a matter discussed elsewhere (Collins, 2011b). It might even be imagined that the line from the Convergence Point to the main pyramid field marked a processional route of some kind. If so, then could the entourage have entered the plateau via the extraordinary megalithic gateway in the Wall of the Crow, which lay on the north side of the Heit el-Ghurab settlement next to Gebel el-Qibli? Clearly, any advancing procession could not 


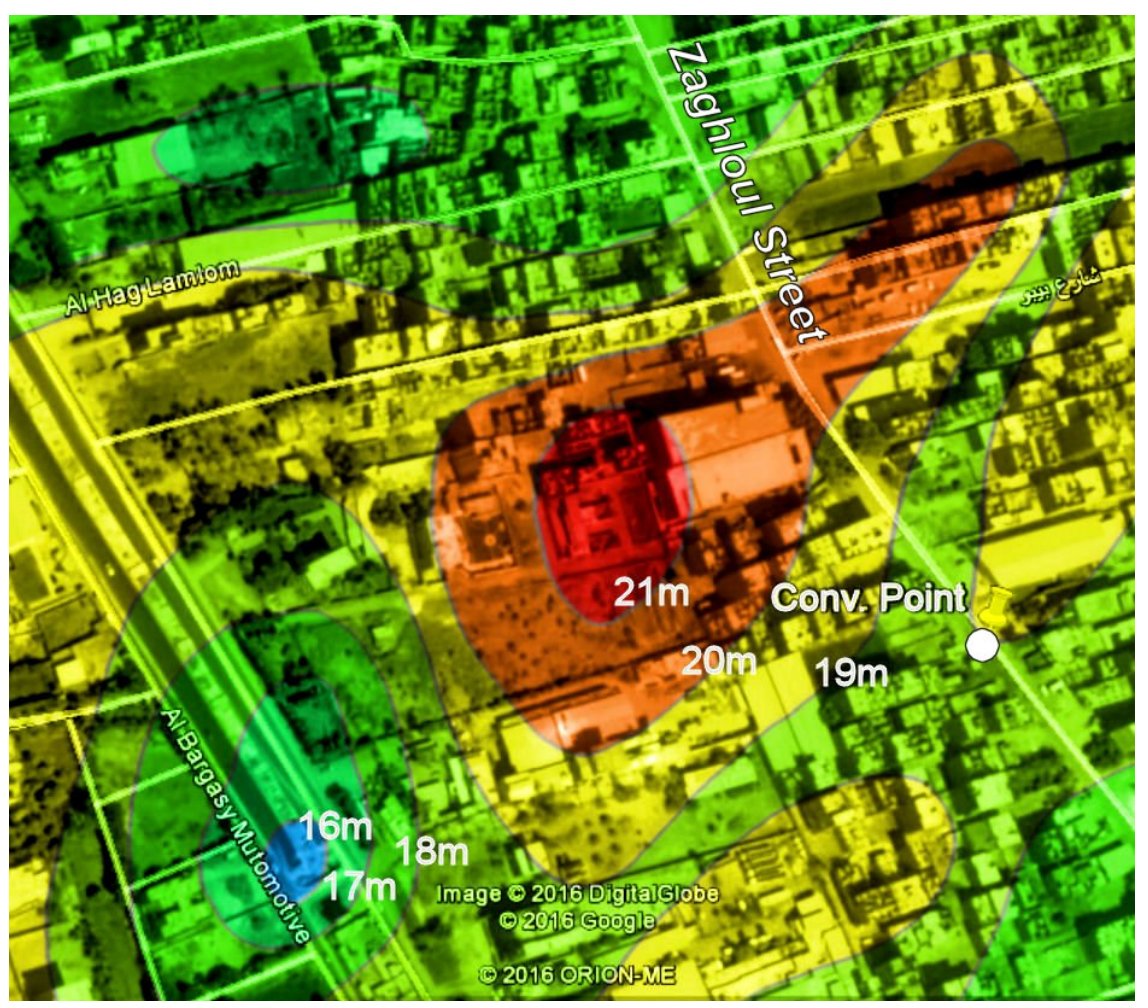

Figure 12. Contours showing heights above sea level in the area of the convergence point on Zaghloul Street, south of Kafr el-Gebel. Note the land elevation some $120 \mathrm{~m}$ west-northwest of the Convergence Point, which highlights a raised area $21 \mathrm{~m}$ or more above sea level (satellite image credit: Google Earth/Digital Globe, 2016).

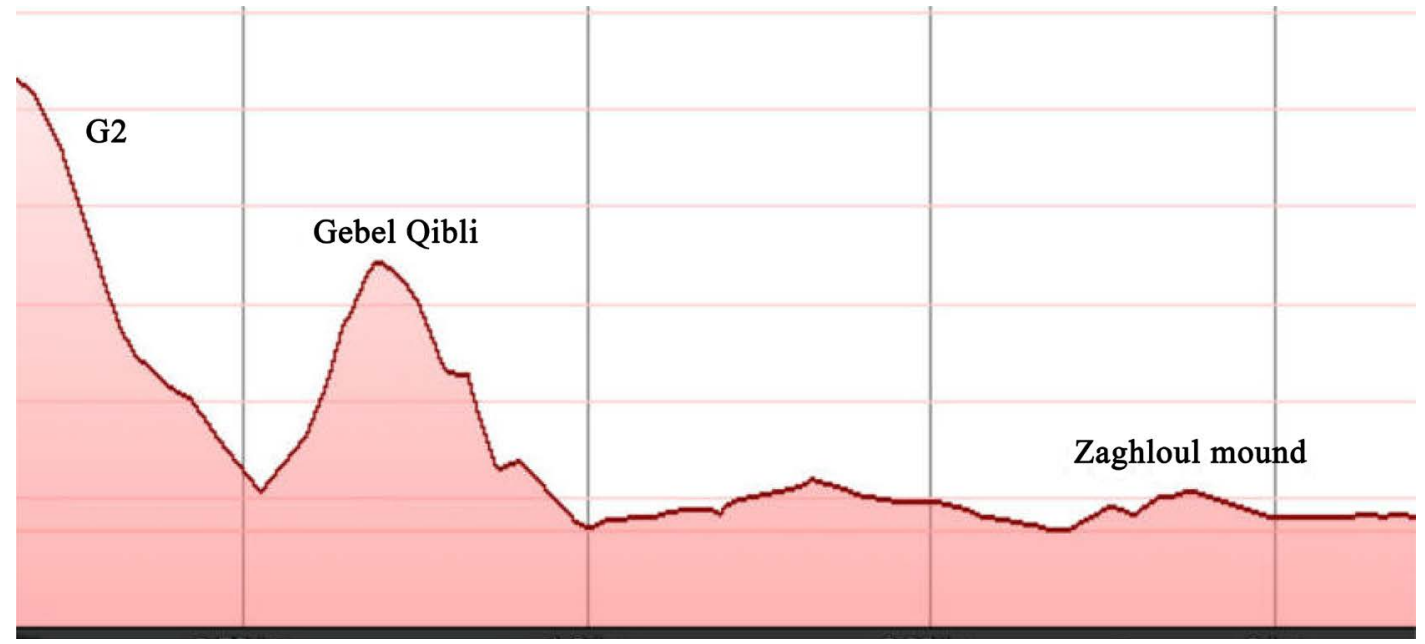

Figure 13. Elevation profile from the area of the Convergence Point to the peak of G2. Note the profile of the Zaghloul Street Mound. The bump between Gebel el-Qibli and the Zaghloul Street Mound is a large wooded area (pic credit: Google Earth/Digital Globe, 2016).

have gone over the top of Gebel el-Qibli, so this point of entrance onto the plateau makes absolute sense, the wall acting arguably as a border between the land of the living and the realm of the dead. If correct, this is additional evidence that ancient Egyptians during the age of Khufu saw the placement of the Giza Pyramids as important when viewed from the south, a fact lending further weight to the idea that it was the stars of the northern night sky that featured in any ground-sky correlations at Giza, with those of Cygnus being the most obvious candidates. 


\section{Discussion and Conclusions}

Orofino and Bernardini in their study of possible star correlations at Giza use statistical data to confirm the Orion Correlation Theory and dismiss any connection between the Cygnus wing stars and the pyramid peaks. Very clearly, these findings are at odds with those outlined in this current paper. The authors ably show how visual correlations can be accurately confirmed by the use of good astronomical star maps and the known positions of the pyramids. There is no need to employ indirect mathematical methods or scaled maps, from which calculations have to be made which establish only the probability of the existence of correlations. In the authors' estimations, it was considered of primary importance to use ground to sky correlations that would have been visible and thus meaningful to the ancient Egyptians of the pyramid age. This was found only in the CygnusGiza Correlation at Giza, and not in the Orion Correlation Theory.

From these findings, it seems extremely unlikely that the star-to-peak matches between the Cygnus wing stars and the three main pyramids at Giza in both the horizontal and vertical plane exist by chance alone. Indeed, the authors demonstrate how the Cygnus-Giza Correlation functions not just in two dimensions, but in a three-dimensional reality. In this manner, the stars of Cygnus are likely to have formed an integral role in the pyramid field's grand design from its very inception. The possible purpose behind the employment of the Cygnus stars at Giza is adequately outlined elsewhere (Collins, 2009, 2011a).

\section{Acknowledgements}

The authors thank Juan Antonio Belmonte, Debbie Benstead-Cartwright, Catherine Hale, Joan Hale, Robert Hale, Greg Little, Kim Prachniak, Nigel Skinner-Simpson, Jan Summers, James van Auken, Richard Ward, and Caroline Wise, for their help in the preparation of this paper.

\section{Picture Copyright}

All pictures appearing in this paper are the copyright of the authors unless otherwise stated in the accompanying caption.

\section{References}

Agnew, H. C. (1838). The Quadrature of the Circle in the Configuration of the Great Pyramids of Gizeh. London: Longman, Orme, Brown, Green, \& Longmans.

Aigner, T. (1983). A Pliocene Cliff-Line around the Giza Pyramids Plateau, Egypt. Palaeogeography, Palaeoclimatology, Palaeoecology, 42, 313-322. http://dx.doi.org/10.1016/0031-0182(83)90029-9

Ballard, R. (1882). The Solution of the Pyramid Problem, or Pyramid Discoveries, With a New Theory as to Their Ancient Use. New York: John Wiley.

Bauval, R. G. (2006). The Egypt Code. London: Century Publishing.

Bauval, R., \& Gilbert A. (1994). The Orion Mystery: Unlocking the Secrets of the Pyramids. London: Heinemann.

Clark, R. N. (2010). Notes on the Resolution and Other Details of the Human Eye.

http://www.clarkvision.com/articles/eye-resolution.html

Collins, A. (2006). The Cygnus Mystery. London: Watkins.

Collins, A. (2009). Beneath the Pyramids. Virginia Beach, VA: 4th Dimension Press.

Collins, A. (2011a). Giza’s Cosmic Blueprint Revealed: Part One-Is Cygnus the Key to Unlocking the Pyramids’ Grand Unified Plan? http://www.andrewcollins.com/page/articles/cygnus_blueprint.htm

Collins, A. (2011b). Giza’s Cosmic Blueprint Revealed: Part Two-The Search for Egypt’s Mound of Creation.

http://www.andrewcollins.com/page/articles/cygnus_blueprint_2.htm

Dash, G. (2011). Solar Alignments of Giza. AERAgram, 12, 3-8.

Goodman, D. (2007). Survey: The GPMP Surveying and Mapping Control Datums. In Lehner, M., \& Wetterstrom, W. (Eds.), Giza Reports: Giza Plateau Mapping Project. Volume 1: Project History, Survey, Ceramics and Main Street and Gallery III. 4 Operations (pp. 95-101). Boston, MA: AERA.

Goodman, D., \& Lehner M. (2007). The Survey: The Beginning. In Lehner, M., \& Wetterstrom, W. (Eds.), Giza Reports: Giza Plateau Mapping Project. Volume 1: Project History, Survey, Ceramics and Main Street and Gallery III. 4 Operations (pp. 97-98). Boston, MA: AERA. 
Goyon, G. (1970). Nouvelles Observations relatives a l’Orientation de la Pyramide de Cheops. Revue D’Egyptologie, 22, 8598.

Hawass, Z. (1997), The Discovery of the Harbors of Khufu and Khafre at Giza. In Berger, C., \& Mathieu, B. (Eds.), Études sur l'Ancien Empire et la nécropole de Saqqâra_Dédiées à Jean-Philippe Lauer. Vol. I. Orientalia Monspeliensia IX (pp. 245-256). Montpellier: Université Paul Valéry.

Hawass, Z., \& Lehner M. (1994). The Sphinx: Who Built It and Why? Archaeology Magazine, 47, 30-41.

Hawass, Z., \& Senussi, A. (2008). Old Kingdom Pottery from Giza. Cairo, Egypt: American University in Cairo Press.

Legon J.A.R. (1979). The Plan of the Giza Pyramids. Archaeological Reports of the Archaeology Society of Staten Island, 10, 1. http://www.legon.demon.co.uk/gizaplan.htm

Lehner, M. (1985). A Contextual Approach to the Giza Pyramids. Archiv fur Orientforschung, 32, 136-158.

Lehner, M. (1997). The Complete Pyramids. London: Thames \& Hudson.

Lehner, M. (2011). Giza, Meter by Meter. AERA. http://www.aeraweb.org/gpmp-project/giza-meter-by-meter/

Lehner, M. (2013). The Heit el-Ghurab Site Reveals a New Face: Lost Port City of the Pyramids. AERAgram, 14, 2-6.

Lehner, M. (2014) On the Waterfront: Canals and Harbors in the Time of Giza Pyramid-Building. AERAgram, $15,14-23$.

Love, S. (2006). Stones, Ancestors and Pyramids: Investigating the Pre-Pyramid Landscape of Memphis. In Bárta, M. (Ed.). The Old Kingdom Art and Archaeology: Proceedings of the Conference, Prague, 31 May-4 June 2004 (pp. 209-18). Prague, Czech Republic: Czech Institute of Archaeology.

Lutley, K., \& Bunbury, J.M. (2008). The Nile on the Move. Egyptian Archaeology, 32, 3-5.

Miracle, R. (2011). Something Old, Something New, Something Borrowed in Map View: GIS Brings It All Together. AERAgram, 12, 10-12.

Orofino, V. \& Bernardini, P. (2016). Archaeoastronomical Study of the Main Pyramids of Giza, Egypt: Possible Correlations with the Stars? Archaeological Discovery, 4, 1-10. http://dx.doi.org/10.4236/ad.2016.41001

Petrie, F. (1883). The Pyramids and Temples of Gizeh. London: Field \& Tuer; New York: Scribner \& Welford.

Quirke, S. (2001). The Cult of Re: Sun-Worship in Ancient Egypt. London: Thames \& Hudson.

Schaefer, B. (1993). Astronomy and the Limits of Vision. Vistas of Astronomy, 36, 311-361.

http://www.sciencedirect.com/science/article/pii/008366569390113X http://dx.doi.org/10.1016/0083-6656(93)90113-X

Von Beckerath, J. (1997). Chronologie des pharaonischen Ägypten: Die Zeitbestimmung der ägyptischen Geschichte von der Vorzeit bis 332 v. Chr. Darmstadt, Germany: Philipp von Zabern. 